\title{
Géneros jurídicos y traducción (alemán-español)
}

\author{
Mar Jiménez Domínguez \\ Universidad de Córdoba \\ 162jidom@uco.es
}

https://dx.doi.org.10.12795/futhark.2020.i15.07

Fecha de recepción: 29.09 .2020

Fecha de aceptación: 3.11 .2020

Resumen: En el ámbito de la traducción jurídica, la clasificación de los textos supone una herramienta útil para el traductor durante el proceso de documentación, pues le permite un acercamiento al contexto en el que se utiliza y desarrolla el texto. Por ello, mediante la compilación de un corpus textual formado por demandas en alemán y español, hemos analizado la situación comunicativa y los rasgos legales que conforman esta clase textual, lo cual nos ha permitido desarrollar un modelo de clasificación en el que enmarcar el texto demanda.

Palabras clave: género jurídico, traducción jurídica, demanda, clasificación

\section{Legal textual Genres and Translation (German-Spanish)}

Abstract: In the field of legal translation, the classification of texts is a useful tool for the translator during the documentation process, as it allows him/her to get closer to the context in which the text is used and developed. Therefore, through the compilation of a textual corpus formed by German and Spanish lawsuits, we have analyzed the communicative situation and de legal features that make up this textual class, which has allowed us to develop a classification model in which to frame the text lawsuits.

Keywords: textual genre, legal translation, lawsuit, classification.

Sumario: Introducción. I. Conceptos taxonómicos en disputa: género, tipo y registro. I.I. El género jurídico y otras categorías de clasificación: supragénero y subgénero. 2. Algunas cuestiones previas: selección y análisis de los textos. 3. Propuesta de modelo de clasificación del género demanda. 3.I. Familia de géneros. 3.I.I. Supragénero. 3.I.2. Género. 3.I.3. Subgénero. 4. Resultados. Conclusiones 


\section{Introducción}

La traducción jurídica es una especialización que requiere de un alto grado de cualificación y exige a la persona que la ejerce poseer un profundo conocimiento tanto de la terminología como de la compresión entre los diferentes ordenamientos jurídicos de las lenguas de trabajo. De igual forma ocurre en la enseñanza y didáctica de esta rama de especialización, pues los alumnos suelen encontrar dificultades a la hora de contar herramientas de documentación y adquirir competencias suficientes para afianzar conocimientos y elegir, por último, el proceso traductor.

Ante la traducción de textos que, por lo general, parecen no forman parte de la cotidianidad, el traductor o el estudiante deberá, en primer lugar, entender con que pretexto legislativo se formula el TO, así como también identificar el rasgo jurisdiccional que lo dota. En este sentido, no siempre existen equivalencias legislativas o jurisdiccionales en la LM, por lo que es necesaria la creación de mecanismos que ayuden a la comprensión del TO y puedan trasladarse correcta y legalmente al TM. Partiendo de esta realidad, y tomando como lenguas de trabajo el alemán y el español (ambas herederas del Derecho Romano), es posible establecer las siguiente hipótesis: por un lado, el análisis sobre los textos jurídicos españoles desde una perspectiva lingüística y textológica, ayudará al traductor y al alumnado de traducción jurídica a comprender el TM: por otro, dicho análisis aplicado a un modelo de clasificación basado en la jerarquización desde lo abstracto a lo concreto, les permitirá conocer y afianzar conocimientos de ordenamiento jurídico del TM para así poder hallar más fácilmente las equivalencias del TO.

Para abordar la propuesta de clasificación de los géneros jurídicos aplicado al caso práctico de la demanda española, hemos ordenado el presenten trabajo en cinco secciones. En primer lugar, abordaremos el concepto de 'género textual' y la diferencia que se establece entre éste y otros conceptos taxonómicos, como el 'tipo textual' o el 'registro'. De igual forma, profundizaremos sobre la relación del Derecho y los géneros textuales y la importancia de contar con otras categorías de clasificación para el proceso traductor de documentación. En segundo lugar, expondremos la selección del corpus en que se ha basado el caso práctico, asi como también el análisis textual nuestra TM, la demanda española. En tercer lugar, el grueso del estudio lo constituye el desarrollo de nuestra propuesta de clasificación de los géneros jurídicos y los criterios de identificación que se han utilizado para delimitar cada nivel. Finalmente, a tenor de los resultados obtenidos y teniendo en cuenta nuestra hipótesis de partida, estableceremos las oportunas conclusiones. 


\section{Conceptos taxonómicos en disputa: género, tipo y registro}

Si analizamos los significados que se le atribuyen al concepto de género textual, solemos encontrarnos con que éste suele confundirse con otros, como son el 'tipo de texto' o el 'registro'. Por ello y como consecuencia de la falta de consenso aún latente por parte de los estudiosos, consideramos necesario señalar las diferencias existentes antes de adentrarnos en los géneros jurídicos y su posterior modelo de clasificación.

El concepto de 'registro' aplicado al ámbito lingüístico desde una óptica sistémico-funcional tiene su origen en la escuela de Sidney y fue puesto en valor por Halliday (1964, 1978, 1985). Para el autor el texto siempre se produce en un contexto situacional determinado y representado por tres dimensiones: el campo, el tenor y el modo. Estos tres factores situacionales conforman el registro, el cual variará según el uso de la lengua. En el presente estudio, tomaremos el contexto situacional basado en una noción más amplia en las que el tenor y el modo no son criterios determinantes a la hora de clasificar los textos y denominaremos lo que para Halliday es el campo, 'función textual'. En este caso, basada en la interacción social que, a su vez, es heredera de la corriente cognitiva-procedimental (Iris Holl, 2007: 212). Según la autora (íbid.), "la función de un texto se concibe como el efecto que produce un contexto concreto de interacción social, en su funcionamiento para la realización de determinadas metas comunicativas sociales y objetivo individuales (Heinemann/Viehweger 199I;148; Ciapuscio 2003:98)”. De forma más clara, Elena (2007 : 109$)$ se pregunta "para qué se produce el texto". Por tanto, la función textual también lleva implícita la finalidad del texto.

Por el contrario, el 'tipo de texto' ha sido tomado como concepto amplio, tal y como lo defiende Mash (1999) o como propósito retórico principal, según la corriente que siguen Werlich (1976) y Hatim y Mason (1990) y que proponen la clasificación de textos expositivos, argumentativos y exhortativos. Por suparte, Swales (1990), Bahtia (1993) y Biber (1995), el 'tipo textual' corresponde a lo relacionado con rasgos lingüísticos o léxicos comunes, mientras que los factores basados en criterios no lingüísticos o extratextuales se corresponden con la noción de 'género'.

Finalmente y ahondado en nuestra propuesta objeto de estudio, cabe destacar que el concepto de 'género' aplicado más allá del ámbito literario tiene su origen en el Estudio de la Textología Contrastiva y en el Inglés para Fines Específicos (Cobos López, 2012: 77), disciplinas que cobraron interés a principios de la década de los 70 y que por el componente sociocultural propio de los textos, han servido a estudios posteriores relacionados con la disciplina traductológica y las convenciones de género. En este sentido, cabe destacar la aportación de Hoffmann (1991:5) en torno al valor de la evolución histórica y la 
convencionalización propia de los géneros textuales, así como la definición de Hurtado Albir (200I: 637):

[Los géneros textuales] son agrupaciones textuales que comparten la misma situación de uso, con emisores y receptores particulares, que pertenecen a un mismo campo y/o modo textual y que tienen características textuales convencionales, especialmente de superestructura y de formas lingüísticas fijas; generalmente comparten la(s) misma(s) función(es) y el tono textual. Pueden dividirse a su vez en subgéneros y agruparse en torno a categorías supragenéricas

Por los motivos expuestos, consideramos que las clasificaciones por géneros textuales son mucho más precisas que las tipologías, pues además de tener como elemento investigador principal las convenciones de género — fundamentales para los profesionales de la traducción y para la enseñanza de ésta-, también sirven como restricción a la estructura discursiva del texto (Trosborg: 1997:10). Asimismo, también consideramos esencial tratar los términos taxonómicos que rigen las categorías superiores o inferiores de los géneros textuales, como pueden ser el supragénero y el subgénero

\section{I.I. El género jurídico y otras categorías de clasificación: supragénero y subgénero}

Tras intentar esclarecer los conceptos anteriores, pasamos a aplicar el concepto de género a los textos jurídicos. Es evidente que el Derecho es una ciencia social que viene determinada por las costumbres de una sociedad, pues como afirma Borja Albi (2007): "se puede decir, por tanto, que redactar textos, recopilarlos y clasificarlos han sido actividades vinculadas, desde tiempos inmemoriales, al mundo jurídico". Por ello, a la hora de analizar textos de carácter jurídico, debemos tener en cuenta que éstos poseen convenciones, clichés y estructuras recurrentes heredades de la cultura jurídica que se ha producido en esa comunidad. En definitiva, nos encontramos ante textos muy estereotipados, repetitivos y caracterizados por un lenguaje arcaico y fosilizado (Hurtado Albir: 2017: 492).

Con motivo de los rasgos anteriores expuestos y teniendo en cuenta que cada realización textual perteneciente al ámbito jurídico responde a un alto grado de convencionalismo, las categorías de supragénero y subgénero se tornan fundamentales en las investigaciones de los géneros textuales, pues éstos no pueden estudiarse de manera independiente a causa de su propia jerarquización (Cobos López, 2014:80).

Por su parte, Swales (1990) ya aludía a una etiqueta supragenérica como una macroagrupación de textos que de manera intuitiva nos pudiera orientar en su clasificación. Por otro lado, Hurtado y Borja (1998:342; 2000:133) también proponen una clasificación de géneros jurídicos agrupados en siete categorías 
supragenéricas caracterizadas por el uso que hacen los juristas de los textos, estas son: textos normativos, jurisprudencia, textos judiciales, textos de aplicación del derecho (público y privado) y textos doctrinales. A modo de ejemplo y teniendo en cuenta nuestro objeto de estudio, dentro de la categoría supragenérica - textos judiciales-, se incluyen los géneros denuncia, demanda, querella, auto, sentencia, etc. Esto muestra que la categoría supragenérica no determina las características propias del género, pues la demanda o la denuncia son escritos procesales que inician un proceso $y$, en cambio, la sentencia es la resolución de un juez $\circ$ un tribunal que finaliza dicho proceso. A nuestro modo de ver, consideramos que esta categoría superior resulta muy útil para el traductor, ya que le proporciona un acercamiento al contexto en el que se produce el texto y, por tanto, lo podría utilizar como punto de partida en su proceso documentación.

Por otro lado, V. Bathia (1993: 14) aludía a los subgéneros como una subcategoría con un propósito comunicativo concreto: "minor changes or modifications in the communicative purpose". El autor (1993: 209) también proporciona un criterio clasificador muy importante que, además, lo relaciona con los textos jurídicos: "clarification of cognitive structuring, which may include the use of textualmapping devices". Por otro lado, coincidimos con la definición que aporta Gamero (1998: 157), ya que alude a que los subgéneros son "variantes que surgen dentro de un género", pues como afirma años más tarde junto a Ezpeleta (2007: II), las variaciones que se dan suelen ser o bien por la temática o bien por la complejidad de un mismo texto.

\section{Algunas cuestiones previas: selección y análisis de los textos}

La elección de las demandas como caso práctico viene determinado por los estudios de Holl (2007) y Cobos López (20I2) en torno al análisis textual y contrastivo de las sentencias civiles (DE-ES, lo que nos ha llevado a analizar la demanda como documento previo al objeto de estudio de las autoras. Por ello, compilamos un corpus formado por seis demandas, tres en español y tres en alemán, cada una de ellas perteneciente a una jurisdicción de rango civil.

Para el análisis de las características lingüísticas, textuales y legislativas de la demanda española hemos tenido en cuenta el postulado de W. Franke que Cobos López (2012: 87-88) utiliza para describir la "clase textual textos judiciales".

- Kommunikationssituation; (situación comunicativa)

Por situación entendemos la totalidad de los hechos o circunstancias sociales, temporales, locales o institucionales que suceden entre el emisor y el receptor en el ámbito de la comunicación. Por un lado, en el caso que nos concierne, debemos tener en cuenta que cuando se inicia una demanda es porque 
una persona física o jurídica tiene voluntad de reclamar un derecho (económico o de materia) a otra persona física o jurídica. Por ello, cuando se procede a interponer una demanda debemos tener en cuenta que es de carácter obligatorio que exista un emisor y un receptor, a saber: un demandante y un demandado. Además, en la mayoría de los casos, también será necesaria la participación obligatoria de un abogado y un procurador. Cuando esto sea así, el primero pasará a ser el autor de la demanda, es decir, aquella persona con conocimiento jurídicos que es capaz de redactar el texto utilizando estructuras jurídicas $y$, el segundo, el representante procesal. Este documento va dirigido a un juzgado específico que, a su vez, cuenta con un tribunal, que será el que dé resolución a la reclamación de la parte demandante. Por ello, la trama comunicativa se verá condicionada por las formaciones sociales de los interlocutores y el contexto situacional en el que se encuentren, pues, por ejemplo, el tono entre la relación abogado-cliente distará del que los abogados utilicen para interpelar al juez.

- Kommunikationsziel (objetivo de comunicación).

En este caso, existen dos objetivos principales de comunicación: I) hacerle saber a la parte demandante la reclamación de la parte demandada y 2) suplicar al juzgado una resolución del conflicto económico o de materia surgido entre ambas partes procesales. Asimismo, existen otros objetivos secundarios que se establecen por la propia caracterización de la demanda, como, por ejemplo, que el demandante sea capaz de exponer a su abogado de forma clara, concisa y detallada los hechos por los cuales quiere interponer la demanda o, en referencia a al demandado, que este sea capaz de exponerle a su abogado información veraz para su defensa.

- Kommunikationsmittel (medio de comunicación).

La demanda es un escrito procesal, por tanto, siempre se deberá presentar ante juzgado vía escrito que previamente haya redactado un abogado o bien, vía formulario que debe rellanar la parte demandante. Tal y como hemos expuesto anteriormente, esta situación dependerá tanto de jurisdicción a la que se interponga la demanda como de la petición que se haga de esta. Por otro lado, debemos tener en cuenta que el texto demanda siempre estará constituido por unidades léxicas y estructuras lingüísticas tipificadas que, de carácter obligatorio, deberá incluir el texto demanda para que se le considere como tal ante el órgano competente al que vaya dirigida.

\section{Propuesta de modelo de clasificación del género demanda}

A continuación, exponemos el modelo de clasificación que Ezpeleta Piorno y Gamero Pérez (2004: 5) utilizaron para clasificar textos en el ámbito técnico: 


\begin{tabular}{|c|c|c|c|}
\hline & DENOMINACIÓN & $\begin{array}{c}\text { CRITERIOS DE } \\
\text { INDENTIFICACIÓN }\end{array}$ & $\begin{array}{l}\text { EJEMPLO EN EL } \\
\text { ÁMBITO TÉCNICO }\end{array}$ \\
\hline $\begin{array}{l}\text { NIVEL } \\
1\end{array}$ & Familia de géneros & $\begin{array}{l}\text { Finalidad } \\
\text { comunicativa }\end{array}$ & $\begin{array}{l}\text { Documentos de uso } \\
\text { industrial }\end{array}$ \\
\hline $\begin{array}{l}\text { NIVEL } \\
2\end{array}$ & Supragénero & $\begin{array}{l}\text { Finalidad } \\
\text { comunicativa, canal }\end{array}$ & Acta \\
\hline $\begin{array}{l}\text { NIVEL } \\
3\end{array}$ & Género & $\begin{array}{l}\text { Finalidad } \\
\text { comunicativa, } \\
\text { situación, } \\
\text { participantes (emisor, } \\
\text { receptor y resto de } \\
\text { participantes, en su } \\
\text { caso) }\end{array}$ & Acta de ensayo \\
\hline $\begin{array}{l}\text { NIVEL } \\
4\end{array}$ & Subgénero & $\begin{array}{ll}\text { Complejidad } & \circ \\
\text { variación temática }\end{array}$ & $\begin{array}{l}\text { Acta de ensayo de } \\
\text { producto farmacéutico }\end{array}$ \\
\hline
\end{tabular}

Tabla I. Modelo de clasificación de los géneros de Ezpelta y Gamero (2007: 8-10)

Espelta Piorno y Gamero Pérez (2004: 8-10) definían como sigue sus niveles de clasificación:

El de familia de géneros, se corresponde con el grado máximo de abstracción. Agrupa a un colectivo de textos que tienen en común una finalidad comunicativa determinada en un contexto de uso socioprofesional específico [...] El segundo nivel corresponde al supragénero. Se trata de una abstracción que representa los rasgos mínimos comunes a todos los géneros que se agrupan por debajo de él. Los rasgos comunes son finalidad comunicativa y canal. [...] El tercer nivel corresponde a los géneros. [...] El cuarto nivel corresponde a los que denominamos subgéneros, que vienen definidos por el campo temática concreto o bien por la complejidad de temática.

A nuestro modo de ver, consideramos que este modelo de la clasificación es claro, preciso y muy ambicioso. Todos los niveles que exponen las autoras están jerarquizados de mayor a menor abstracción, por lo que los criterios de clasificación están agrupados desde lo más abstracto a lo más concreto. Además, al contar con cuatros niveles clasificatorios, se proporcionan un reparto semántico más equitativo $y$, por tanto, más preciso, de cada uno de estos. Por ello, hemos decidido realizar el análisis de la demanda basándonos en la propuesta de las autoras. Sin embargo, hemos realizado algunos cambios sobre los criterios de identificación, pues en nuestro caso tratamos un texto del ámbito jurídico y los 
criterios a tener en cuenta para describir la realidad extratextual e intertextual se han visto alterados.

A continuación, presentamos nuestro modelo de análisis y sus respectivos criterios de identificación:

\begin{tabular}{|c|c|c|c|}
\hline \multicolumn{4}{|c|}{ ÁRBOL JURÍDICO ${ }^{1}$} \\
\hline & DENOMINACIÓN & $\begin{array}{l}\text { CRITERIOS DE } \\
\text { IDENTIFICACIÓN }\end{array}$ & $\begin{array}{c}\text { EJEMPLO EN EL } \\
\text { ÁMBITO } \\
\text { JURÍDICO }\end{array}$ \\
\hline $\begin{array}{l}\text { NIVEL } \\
1\end{array}$ & Familia de géneros & Contexto situacional & Textos judiciales \\
\hline $\begin{array}{l}\text { NIVEL } \\
2\end{array}$ & Supragénero & $\begin{array}{l}\text { Contexto situacional, } \\
\text { función textual }\end{array}$ & $\begin{array}{l}\text { Escrito procesal } \\
\text { de inicio del } \\
\text { proceso }\end{array}$ \\
\hline $\begin{array}{l}\text { NIVEL } \\
3\end{array}$ & Género & $\begin{array}{l}\text { Contexto situacional } \\
\text { (situación comunicativa: } \\
\text { emisor, receptor y resto } \\
\text { de participantes; campo; } \\
\text { modo y tono), función } \\
\text { textual. }\end{array}$ & Demanda \\
\hline $\begin{array}{l}\text { NIVEL } \\
4\end{array}$ & Subgénero & $\begin{array}{l}\text { Complejidad o variación } \\
\text { temática }\end{array}$ & $\begin{array}{lr}\text { Demanda a la } \\
\text { jurisdicción civil, } \\
\text { social } \\
\text { contencioso- } \\
\text { administrativa }\end{array}$ \\
\hline
\end{tabular}

\section{I. Familia de géneros}

En nuestra propuesta de clasificación, hemos decidido mantener la jerarquía de los niveles del modelo de análisis. Al igual que Ezpeleta y Gamero (2004: 5), la familia de géneros constituye el grado máximo de abstracción, ya que agrupa un conjunto de textos que comparten, es nuestro caso, un mismo contexto situacional

${ }^{1}$ El concepto de árbol jurídico del grupo GENTT ha sido tomado solo como término taxonómico para designar un nombre a nuestra propuesta de modelo de clasificación.

Futhark I5 (2020) 
que, conforme descendamos de nivel, determinará la situación comunicativa (Hurtado Albir: 2017: 34). Asimismo, cabe destacar que exponemos aquí una noción de situación amplia, tal y como la entiende Iris Holl (200 I I: 2I4): "no solo incluye factores ambientales directos (tiempo, lugar), sino, sobre todo, conocimientos sobre esferas comunicativas, instituciones y formaciones sociales" 2 y por el ámbito que estamos tratando, también añadimos administraciones. Por ejemplo, los textos judiciales forman una familia compuesta por géneros que comparten un mismo contexto situacional, a saber: textos que se dan dentro de un marco perteneciente o relacionado con el ámbito judicial y en el que las esferas comunicativas se caracterizan por el nivel de formación de quienes las ocupan, que pueden ir de experto a lego. Como podemos observar, en este nivel el contexto situacional no determina ninguna situación comunicativa, ya que la lista de textos judiciales es muy amplia. Por ello, los rasgos concretos de materialización lingüística compartidos son escasos, ya que solo comparten rasgos situacionales muy generales. Ezpeleta y Gamero (2004: 5) aludían a que esta categoría era de suma importancia porque "ofrece un contexto para explicar la relación entre los diferentes géneros y entre unas familias y otras, lo cual puede resultar crucial en muchas ocasiones para que el traductor comprenda el sentido de un determinado texto en su contexto de uso". Teniendo en cuenta esta consideración de las autoras, consideramos que el contexto situacional se adapta también a su definición y conocerlo es de gran utilidad para el traductor.

\section{I.I. Supragénero}

El segundo nivel corresponde al supragénero, se trata de un nivel que aúna todos los rasgos comunes de los géneros que se encuentran por debajo de él (íbid). La familia de textos judiciales presenta los siguientes supragéneros: los escritos procesales de inicio del proceso, de contenido jurisdiccional, de impugnación, de auxilio judicial, de notificación y de constancia ${ }^{3}$. Por ejemplo, el contexto situacional en el que se desarrolla un escrito procesal de inicio de proceso determina una situación comunicativa aún abstracta, pues consiste en que un participante independientemente de cuál sea su motivación - presente un escrito ante una administración pública u órgano competente en el que las esferas comunicativas variarán según la relación de los diferentes interlocutores que, a su vez, condicionarán las diferencias entre las formaciones sociales de estos. En cambio, la

\footnotetext{
2 Por "formaciones sociales" entendemos aquí a que HOLL (20II) hace referencia a lo que HALLIDAY y HASAN (1976) llaman función interpersonal, es decir, el grado de formación socioprofesional que tiene los diferentes interlocutores que intervienen en la situación comunicativa $y$, como esta, variará según los participantes que intervengan.

${ }^{3}$ La enumeración de los supragéneros y los géneros —que expondremos más adelante-, está basada en un artículo de José María Gutiérrez Álvarez, de la Universidad de Passau en Baviera, Alemania para el CIEFE: “El español jurídico: Discurso profesional y académico” (201 I: I62).
} 
función textual (fundada en la interacción social) es formular un escrito "dirigido a un órgano competente" en el que se deberán "exponer unos hechos" para qué así se pueda "iniciar" el proceso — sin especificar que este sea civil o penal-. A diferencia de lo que exponían Ezpeleta y Gamero, al tratarse del ámbito jurídico, debemos tener en cuanta que la finalidad comunicativa de estos textos no es el criterio de identificación más abstracto, pues esta está muy relacionada con factores sociales, situacionales, locales y legislativos que dependerán de los interlocutores que intervengan en el proceso, en la redacción y en la creación de los textos. Como podemos observar, el contexto situacional no determina una situación comunicativa concreta, pero sí establece a un posible emisor y receptor que, a su vez, hace posible establecer las funciones textuales mínimas $y$, como consecuencia, una finalidad. Asimismo, en este nivel se empiezan a observar similitudes en cuanto a los rasgos lingüísticos comunes y los factores extratextuales de los textos, pero su objetivo no es abordar las características específicas, ya que la forma que pueden adquirir los textos puede variar demasiado.

\section{I.2. Género}

El tercer nivel corresponde a los géneros. En primer lugar, el contexto situacional del género demanda sí establece una situación comunicativa concreta a diferencia de lo que ocurría en el nivel I y 2 - . En este nivel se puede analizar al emisor (demandante) y al receptor potencial (demandado), asimismo intervienen otros participantes como el emisor paralelo (el autor material del texto, en la mayoría de los casos un abogado) o intermedios (procurador) y receptor intermedio (procurador) y receptor paralelo (abogado del demandante, tribunal de rango civil). Además, podrían también intervenir comunicadores satélite, como pueden ser los testigos. Por ello, el texto estará dotado de un tono formal, ahora bien, las esferas comunicativas que se produzcan durante la situación comunicativa variarán según los interlocutores, por ejemplo: cliente-abogado (lego-experto) labogado-juez (experto-experto). El modo textual será escrito y el campo -un texto que se desarrolla en el ámbito judicial- será el que concrete la función textual y la finalidad, factores que determinarán la dimensión pragmática: un escrito que inicia un proceso civil que tiene como función textual "exponer" unos hechos "dirigidos" a un tribunal para qué dé una resolución a una reclamación (económica o de materia) solicitada por la parte demandante al demandado. Por ello, en este nivel podemos observar que los factores textuales internos como las convenciones de género o la superestructura dependerán de los factores externos expuestos. Asimismo, en este nivel encontramos rasgos de materialización lingüísticas más concretos en lo que cobra sentido realizar un análisis de estos con vistas de crear una herramienta útil para el traductor.

El supragénero escrito procesal de inicio del proceso incluye los géneros demanda, denuncia y querella, que comparten un mismo contexto situacional 
(ámbito judicial en el que se produce un texto que va dirigido a un juzgado u órgano competente). Por ello, cabe destacar que también compartirán las mismas funciones textuales que, cuando se realice el análisis de los tres géneros, se concretarán a causa del campo en el que se desarrolla cada texto y, por tanto, también veremos concretada la finalidad. Además, las esferas comunicativas en las que participen los diferentes interlocutores serán similares en los tres géneros, al igual que el grado de formación social de los interlocutores que participen en estos. Con tal de exponer de forma clara los criterios que hemos expuesto anteriormente para definir y clasificar el género demanda, mostramos a continuación una tabla con las diferencias y similitudes de esta con la denuncia y querella:

\begin{tabular}{|c|c|c|c|}
\hline & Demanda & Denuncia & Querella \\
\hline Emisor & $\begin{array}{l}\text { demandante } \\
\text { (obligatorio que } \\
\text { participe en el } \\
\text { proceso) }\end{array}$ & $\begin{array}{l}\text { denunciante } \\
\text { (no debe participar } \\
\text { en el proceso) }\end{array}$ & $\begin{array}{l}\text { querellante } \\
\text { (obligatorio que } \\
\text { participe en el } \\
\text { proceso) }\end{array}$ \\
\hline Receptor & demandado & denunciado & querellado \\
\hline $\begin{array}{l}\text { Otros } \\
\text { participantes }\end{array}$ & $\begin{array}{l}\text { Abogado y } \\
\text { procurador (cuando } \\
\text { sea necesario), } \\
\text { (testigos), tribunal } \\
\text { que tenga } \\
\text { competencias sobre } \\
\text { el tema en cuestión }\end{array}$ & $\begin{array}{l}\text { autor del texto } \\
\text { (autoridades } \\
\text { competentes) }\end{array}$ & $\begin{array}{l}\text { abogado, } \\
\text { procurador, } \\
\text { (testigos) }\end{array}$ \\
\hline Tono & formal & formal & formal \\
\hline Modo & escrito & escrito/oral & escrito \\
\hline Función/campo & 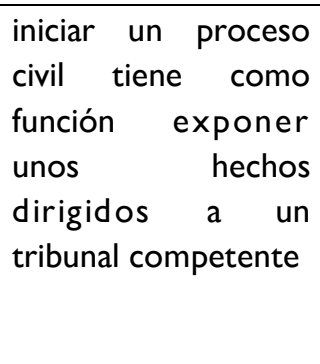 & 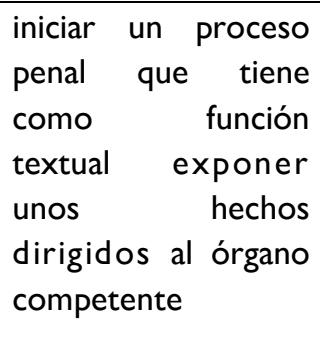 & $\begin{array}{l}\text { iniciar un proceso } \\
\text { penal que tiene } \\
\text { como función } \\
\text { textual exponer } \\
\text { unos hechos a un } \\
\text { dirigidos a un } \\
\text { tribunal } \\
\text { competente }\end{array}$ \\
\hline
\end{tabular}

Futhark I5 (2020) 


\begin{tabular}{|c|c|c|c|}
\hline Finalidad & $\begin{array}{l}\text { para qué dé una } \\
\text { resolución a una } \\
\text { reclamación } \\
\text { (económica o de } \\
\text { materia) solicitada } \\
\text { por la } \\
\text { demandante } \\
\text { demandado. }\end{array}$ & $\begin{array}{l}\text { para declarar unos } \\
\text { hechos que revisten } \\
\text { los caracteres de } \\
\text { delito o falta. }\end{array}$ & $\begin{array}{l}\text { para qué dé una } \\
\text { resolución sobre } \\
\text { la declaración } \\
\text { que el querellante } \\
\text { ha transmitido al } \\
\text { órgano } \\
\text { jurisdiccional } \\
\text { competente } \\
\text { sobre } \\
\text { presunta } \\
\text { comisión de } \\
\text { delito del } \\
\text { querellante. }\end{array}$ \\
\hline
\end{tabular}

Tabla 3. Comparación de los criterios de identificación de los géneros demanda, denuncia y querella.

Por tanto, en este nivel encontramos rasgos de materialización lingüística más concretos a través de los cuales podemos realizar un análisis pormenorizado y estudiar sus características internas. Además, es fundamental tener en cuenta la concreción de la situación comunicativa en el ámbito jurídico, pues será una condición sine qua non que el traductor conozca tanto a los participantes que intervienen en el proceso como la finalidad y la función textual que posee el texto. Resulta cuanto menos interesante añadir en este parte del análisis las investigaciones de Nord (2005) en torno al aspecto funcional del texto, ya que el traductor deberá conocer quién es el cliente de su encargo y para qué —el skoporequiere de la traducción, pues no se adoptarán los mismos métodos traductores para la traducción de una demanda que vaya dirigida a un tribunal que, por ejemplo, la traducción que el demandado pueda solicitar para saber por qué se le está demandado.

\section{I.3. Subgénero}

El cuarto nivel corresponde al subgénero, que viene determinado por el campo temático o por la complejidad que este pudiera tener. En este caso, la demanda puede interponerse a la jurisdicción civil, a la jurisdicción social o a la jurisdicción contencioso-administrativa. Por lo general conservan la misma estructura, aunque como hemos expuesto en el apartado 4.I., en ocasiones esta puede verse alterada por algunas consideraciones mínimas a causa del tema en cuestión. Ezpeleta y Gamero (íbid.), afirmaban que este nivel podía ser significativo, pero en nuestro caso es imprescindible. Debemos tener en cuenta que el género demanda no se formula per se, sino que siempre se interpone a una jurisdicción 
específica, por tanto, los subgéneros serán fundamentales para identificar la temática $y$, en consecuencia, las diferencias prototípicas mínimas que pudieran darse entre una jurisdicción u otra. Cabe destacar que para que una demanda sea considerada como tal, debe contener unos apartados fijos formulados mediante unas unidades léxicas concretas, a saber: exposición de hechos, fundamentos de derecho y petición dirigida a un tribual. Asimismo, sí encontraremos diferencias terminológicas en cuanto al contenido que, pese a que sean cambiante en todas las demandas a causa de los hechos que se expongan y la resolución que se solicite, en algunas ocasiones encontraremos una terminología muy especializada como puede ser, por ejemplo, la biosanitaria, si es una demanda por negligencia médica. Por ello, cabe destacar que en algunos casos nos enfrentaremos a textos híbridos - como la demanda por negligencia médica, que conformaría un género jurídico-médicoque, a pesar de estar regulados por las condiciones jurídicas, su propia condición nace en el seno de otro ámbito de especialización (Balbuena, 20/8). Por ello, el traductor también deberá tener en cuenta estas consideraciones y manejar ambos lenguajes de especialización.

\section{Resultados}

A la luz de los estudios realizados en los apartados epígrafes, el árbol jurídico se constituiría como sigue:

\section{ÁrBOL JURÍDICO 4}

1. Textos judiciales. Contexto situacional: relativo o perteneciente al ámbito judicial en el que las esferas comunicativas variarán según los participantes (de experto a lego).

1.1. Escrito procesal de inicio de proceso: Contexto situacional: un participante redacta un escrito dirigido a un tribunal. Las esferas comunicativas variarán según la formación profesional de los participantes. Finalidad: exponer unos hechos que vayan dirigidos al órgano competente para que se pueda iniciar el proceso.

1.1.1. Demanda: contexto situacional (situación comunicativa: emisor (demandante), emisor mediador (procurador, a veces) y emisor paralelo (abogado, a veces, y tribunal); receptor

\footnotetext{
${ }^{4}$ EzPeleta y Gamero (ibid), no llaman a este esquema "árbol técnico", sino "clasificación de textos técnicos". Nosotras hemos elegido este concepto por las consideraciones que hemos expuesto con anterioridad. De igual forma, también señalamos aquí que la denuncia y la querella no son nuestro objeto de estudio, por tanto, las incluimos en el árbol porque forma parte de él, pero no las analizaremos.
} 
potencial (demandado); receptor mediador (procurador, a veces), receptor paralelo (abogado, a veces, y tribunal), comunicadores satélite (testigos); tono (formal); modo (escrito). Función: iniciar un proceso civil mediante la exposición de unos hechos dirigidos a un tribunal para qué dé una resolución a la reclamación de un derecho (económico o de materia) solicitado por la parte de demandante a la demanda.

1.1.1.1. A la jurisdicción civil: temática: derecho privado (civil y mercantil).

1.1.1.2. A la jurisdicción social: temática: derecho laboral y de la Seguridad social.

1.1.1.3. A la jurisdicción contencioso-administrativa: temática: conflictos entre los ciudadanos y la Administración Pública.

1.1.2. Denuncia

1.1.3. Querella

\section{Conclusiones}

Lo expuesto en los epígrafes precedentes nos conducen a las siguientes conclusiones:

- Tras la revisión de los conceptos taxónomicos, hemos observado como el factor sociocultural de los textos se plasma en las partes estandarizadas de los mismos, es decir, en las convenciones textuales. Por ello, consideramos que los géneros parten de premisas de estudio tangibles, pues los textos se crean, se asimilan y se reproducen por los participantes que conforman las comunidades de hablantes. Mientras que las tipologías textuales parten de criterios más abstractos que dificultan la clasificación.

- La compilación de un corpus textual facilita la tarea del traductor, pues permite desde un primer momento establecer diferencias estructurales y textuales entre ambos textos de trabajo. Por este motivo, el análisis de la situación comunicativa del género demanda en nuestra LO en combinación con el desarrollo de sus características legales ha posibilitado el posterior análisis pormenorizado de las convenciones textuales DE-ES. 
- Tras la consideración anterior, ha quedado patente la necesidad de crear modelos de clasificación operativos constituidos por criterios de identificación que tengan en cuanta la actuación de cada ámbito especializado. Mientras que Ezpeleta y Gamero defendían como eje identificador la finalidad comunicativa en textos pertenecientes al ámbito técnico, se ha comprobado que para analizar y clasificar los géneros jurídicos se debe considerar el contexto situacional y la interacción social en todas las categorías del modelo de análisis, pues la propia naturaleza de los textos jurídicos exige tener en cuenta los factores pragmáticos externos e internos que se establecen en torno a la situación comunicativa. Asimismo, cabe señalar que la jerarquización de los diferentes niveles - familia de géneros, supragénero, género y subgénero- proporciona al traductor una herramienta útil para iniciar el proceso de documentación. Además, consideramos que este factor también se podría emplear en la enseñanza de la traducción de textos jurídicos, ya que debido a la restricción de uso y el alto grado de especialización que se poseen los textos jurídicos, suele ser frecuente que los alumnos ni conozcan ni se hayan enfrentado antes a la comprensión de estas clases textuales. Por lo que consideramos que el modelo propuesto también puede ser una herramienta útil para afianzar la seguridad de los alumnos.

- Por otro lado, en los niveles de clasificación más concretos también se ha comprobado como el enfoque funcional de Nord sobre el skopo permite tanto a los profesionales de la traducción como a los alumnos de esta materia elegir el método traductor más apropiado según el encargo solicitado, pues en el análisis se describen a los participantes y la situación de uso.

- Finalmente, a causa de que la propia naturaleza del Derecho de cada país reside en solucionar los conflictos creados entre los ciudadanos de esa misma comunidad, la temática del texto estará condicionada por este factor y se plasmará en la terminología especializada. Por ello, el traductor, en ocasiones podrá enfrentarse a textos híbridos. 


\section{Referencias bibliográficas}

BALBUENA, M. C. (20I8). "La traducción de textos jurídico-enológicos: géneros textuales y terminología (alemán-español). En: La traducción y la interpretación en contextos especializados, pp. 93-102.

BHATIA, V. K. (1993). "Analysing genre. Language use in professional settings". Londres: Longman.

BORJA, A. (2007). "Los géneros jurídicos”. En: Enrique Alcaraz (ed.) et. al. Las lenguas profesionales y académicas, Pp. I4I-I54. Barcelona: Ariel.

CiAPUSCIO, G. Y KugEL, I. (2002). "Hacia una tipología del discurso especializado:

aspectos teóricos y aplicados". En: Entre la terminología, el texto y la traducción, J. García Palacios y M. Teresa Fuentes (eds.), pp.37-73. Salamanca: Almar.

COBOS, I. (20I2). "La traducción de sentencias: análisis terminológico y textual (alemán-español). Tesis doctoral. Universidad de Córdoba, Córdoba.

ELENA, P. (2008). "La organización textual aplicada a la didáctica de la traducción". En: Quaderns: revista de traducció, núm. I5, pp. I53-I67.

EZPELETA, P. Y GAMERO, S. (2004). “Los géneros técnicos y la investigación basada en corpus: proyecto GENTT”, en R. Gaser, C. Guirado y J. Rey, Insights into Scientific and Technical Translation, Pp. 147-I56. Barcelona: Universitat Pompeu Fabra.

FRANKE, W. (I99I). “Linguistische Texttypologie”, pp. I57-I82. En Brinker, Klaus. 199|. Pp. I57-182.

GuTIÉRREZ, J.M. (20I I). “El español jurídico: Discurso profesional y académico”. En: CIEFE, PP. I50-I66.

HATIM, B. Y MASON, I. (1995). Teoría de la traducción. Una aproximación al discurso. Barcelona: Editorial Ariel.

HOLL, I. (20I I). Textología contrastiva, derecho comparado y traducción jurídica: las sentencias de divorcio alemanas y españolas. Berlín: Frank \& Timme $\mathrm{GmbH}$.

HURTADO, A. (200I). Traducción y traductología. Madrid: Cátedra.

NORD, CH. (2005). Text Analysis in Translation. Theory, Methodology and Didactic Application of a Model for Translation-Oriented Text Analysis. Amsterdam-NY, Rodopi.

REISS, K. Y VEERMER, H. (I99I). Fundamentos para una teoría funcional de la traducción. Madrid: Akal 